\title{
Salvador de Bahía: culturas de rebeldía y descolonización de la educación en un contexto biopolítico de desarrollo urbano desigual
}

Salvador de Babia: Cultures of Rebellion and Decolonization of Education in a Biolopitical Context of Inequal Urban Development

Salvador da Babia: culturas de rebeldia e descolonização da educação em um contexto biopolitico de desenvolvimento urbano desigual

Christy (Chryssanthi) Petropoulou* Marcelo de Jesus Arouca*

Natanael Reis Bomfim ${ }^{* * *}$

Euclides da Silva Santos ${ }^{* * * *}$

Recibido: 30 de abril del 2020

Aprobado: 24 de noviembre del 2020

https://doi.org/10.12804/revistas.urosario.edu.co/territorios/a.9029

Para citar este artículo:

Petropoulou, C., Arouca, M. de J., Bomfim, N. R., \& Santos, E. da S. (2021). Salvador de Bahía: culturas de rebeldía y descolonización de la educación en un contexto biopolítico de desarrollo urbano desigual. Territorios, (44-Especial), 179-211. https://doi.org/10.12804/revistas.urosario.edu.co/territorios/a.9029

* Universidad del Mar Egeo, Departamento de Geografía. Correo electrónico: christy.p@aegean. gr ORCID: https://orcid. org/0000-0001-8144-1382

** Universidad de Estado da Bahia - UNEB, GIPRES. Correo electrónico: maismarceleza@gmail. com ORCID: https://orcid. org/0000-0002-3976-2120

*** Universidad de Estado da Bahia - UNEB, GIPRES. Correo electrónico: nreisbomfim@gmail. com ORCID: https://orcid. org/0000-0002-51229820

**** Universidad de Estado da Bahia - UNEB, CEPAIA. Correo electrónico: euclidessantos23@yaboo. com.br ORCID: https:// orcid.org/0000-0003$1629-400 X$ 
Palabras clave

Culturas de rebeldia; descolonización de la educación; favelas; derecho a la ciudad; Salvador de Babia.

Keywords

Culture of rebellion; decolonization of education; favelas; right to the city; Salvador de Babia.

Palavras-chave

Culturas de rebeldia; descolonização da educação; favelas; direito à cidade; Salvador da Babia.

\section{tersitorias 44 Especial} 180

\section{RESUMEN}

En este trabajo se investigan las posibilidades de descolonización de la educación en las escuelas, teniendo en cuenta el contexto de desarrollo urbano desigual, biopolítico y las resistencias creativas de los valiosos conocimientos culturales de las favelas, barrios de autoconstrucción popular creados por la defensa del "derecho a la ciudad", a través de múltiples prácticas y procesos en Brasil. Diferentes autores las ven como producto de la rápida urbanización, pero pocos señalan su riqueza cultural, ligada a la oprimida tradición afro-indio-americana presente en ellas. Este artículo muestra que las favelas son espacios de resistencia y que nuevas formas de educación intercultural, basadas en las culturas de rebeldía, pueden enriquecer la relación de la escuela con estos barrios. Los métodos de recolección de datos usados para este análisis fueron: estudio bibliográfico, observación participativa y activa, y entrevistas semiestructuradas, llevadas a cabo durante el periodo 2018-2019, en los barrios Estrada das Barreiras (Cabula), Curuzu (Libertad) y San Martin (Fazenda Grande do Retiro), de Salvador de Bahía.

\section{ABSTRACT}

This work investigates the decolonization possibilities of education in schools, taking into account the inequal biopolitical urban development and the creative resistences of the valuable cultural knowledge of the favelas. The favelas of Brazil are popular self-built neighborhoods created by the defense of the «right to the city», through multiple practices and processes. Different authors see them as a product of rapid urbanization, but few point out their cultural wealth, linked to the oppressed Afro-Indian-American tradition present in them. This work shows that favelas are also spaces of resistance and creation of the common and that new forms of intercultural education, based on cultures of rebellion, can enrich the school's relationship with these neighborhoods. The data collection methods used for this analysis were: bibliographic study; participatory and active observation; and semi-structured interviews, carried out during the 2018-2019 period in neighborhoods (barrios) Estrada das Barreiras (Cabula), Curuzu (Libertad) and San Martin (Fazenda Grande do Retiro) in Salvador de Bahia.

\section{RESUMO}

Este artigo investiga as possibilidades de descolonização da educação nas escolas, levando em consideração o contexto de desenvolvimento urbano desigual e biopolítico e a resistência criativa do valioso conhecimento cultural das favelas. As favelas do Brasil são bairros de autoconstrução popular criados pela defesa do "direito à cidade", por meio de múltiplas práticas e processos. Diferentes autores as veem como produto de uma rápida urbanização, mas poucos apontam sua riqueza cultural, ligada à oprimida tradição afro-indígena-americana nelas presente. Este trabalho mostra que as favelas também são espaços de resistência e que novas formas de educação intercultural, baseadas em culturas de rebeldia, podem enriquecer a relação da escola com esses bairros. Os métodos de coleta de dados utilizados para esta análise foram: estudo bibliográfico; observação participativa e ativa; e entrevistas semiestruturadas, realizadas durante o período 2018-2019, na bairros Estrada-das-Barreiras (Cabula), Curuzu (Libertad) y San Martin (Fazenda Grande do Retiro) de Salvador de Bahía.

Christy Petropoulou, Marcelo Arouca, Natanael Bomfim, Euclides da Silva Santos 


\section{Introducción}

Actualmente estamos en una situación de estado de excepción, en la cual, bajo el miedo de la expansión de una nueva pandemia, los planteamientos de la biopolítica parecen muy actuales. Entonces, ¿qué hacen hoy las colectividades subalternas (resistencias creativas) de las periferias urbanas (favelas) en este nuevo contexto? ¡Se organizan en redes de educación y salud por la vida! Un proceso rizomático y glocal con raíces en luchas culturales, políticas y territoriales. En ese marco, se puede decir que la rebeldía construye un contexto de generación de nuevas identidades, por ello, la integración al sistema de educación de este conocimiento producido dentro de las favelas - solidaridad y respeto hacia el otro- es muy importante. Mencionado esto, el presente artículo abre una discusión sobre el papel de las culturas de rebeldía en la educación intercultural, estudiando a las favelas de Salvador de Bahía dentro de un contexto de desarrollo urbano desigual y biopolítico.

Para entrar en materia, la biopolítica es un concepto que Foucault define como "la forma en que hemos intentado, desde el siglo XVIII, racionalizar los problemas planteados a la práctica gubernamental para los fenómenos propios de un grupo de seres vivos constituidos en población: salud, higiene, natalidad, longevidad, razas [...]" (Foucault, 2004, p. 323). La manera en que se arreglan estos problemas está asociada al homo juridicus del liberalismo en el siglo XIX, al homo economicus del neoliberalismo en el siglo Xx (Foucault, 2004), y en la actualidad, al "estado de excepción", la construcción social del homo sacer (Agamben, 1998) que concierne a algunas "poblaciones" nombradas como "excluidas" que en realidad son "precarizadas" mediante procesos sociales, políticos y económicos diferentes (Haesbaert, 2014).

Después de la caída de las Torres Gemelas de Nueva York en el 2001, y el desarrollo del control de la vida cotidiana bajo situación de shock y de excepción, Virilio (2004) habla sobre "la ciudad panique", una ciudad que vive bajo en conmoción y la situación de excepción de derechos humanos inscritos en su constitución. Otras aproximaciones se refieren a "la ciudad alienada" relacionada con el "trabajo alienado" (Petropoulou, 2018b). Mientras que Wacquant (2014) explica cómo se produce el triángulo de marginalidad, etnicidad y penalidad en una ciudad neoliberal; Agamben (2005) describe la "ciudad distópica" ligada a un estado de excepción que produce una vida líquida y desnuda del homo sacer (bomo insacrificable pero matable $)^{1} \mathrm{y}$, luego, la ciudad dirigida de operaciones de muerte, definida por Achille Mbembe (2003) como "necropolítica" - un término que se usa para explicar las formas contemporáneas de subyugación en una situación de "estado de emergencia"-. Dentro de esta situación aparecen "zonas de muerte donde la muerte deviene en el ejercicio
${ }^{1}$ Persona que pueden asesinar sin problema legitimo. 
${ }^{2}$ Refiriéndose a las "clases peligrosas" que surgieron en las revoluciones de 1848 en el norte de Europa, Hobsbawm (2007) explica que, desde el punto de vista de la clase dominante, estaban por definición numerosas, "ignorantes” $y$ "peligrosas". En este caso, el concepto de "ignorante" está más relacionado con el lenguaje dominante y su sistema educativo. Damianakos explica que, al menos en los paises de los Balcanes y del Mediterráneo europeo, existía otra forma de educación dentro de la comunidad, cuyos valores contradecian los valores soberanos emergentes de las élites, lo cual significa que tenian una "tradición de rebeldia".

\section{territarios 44 Especial}

definitivo de dominación y la forma primaria de resistencia", Nuttall et al. (2004) describen esta situación en una ciudad dividida como Johannesburgo.

Existen también algunas aproximaciones respecto a la ciudad gestionada de biopoder (como un ensamblaje de poder disciplinario y biopolítico definido por Foucault, Deleuze y Guatarri), más adaptados a la situación que vive Brasil. Por su parte, Rogerio Haesbaert (2014) describe las sociedades de inseguridad, de biothánato-política de control de territorio y explica cómo se produce la desterritorialización como precarización y control de usufructo territorial desde una perspectiva simbólico-cultural - políticas que no permiten a los habitantes tener el control de sus territorios negándoles el derecho a la ciudad y a la autodeterminación-.

Dentro de todo este proceso histórico de transformación de la ciudad existieron múltiples espacios de resistencia oculta, y redes de resistencia creativa que contribuyeron a la creación actual de la ciudad. Salvador de Bahía es un caso simbólico por sus luchas subalternas en este aspecto. Joselito Teles dos Santos (2018), en su libro $O$ poder da cultura e a cultura no poder, expone la importancia de las culturas oprimidas en las formas de rebeldía y viceversa. Asimismo, Stathis Damianakos (2003) formula que la "tradición de rebeldía" tiene una influencia importante en las culturas populares (Bajtín, 1952/2003) y en los valores relacionados con el espíritu de las llamadas "clases peligrosas" (Hobsbawm, 2007). ${ }^{2}$

De modo que, el primer objetivo de este trabajo es investigar la relación entre culturas populares y tradición de rebeldía en las favelas de Salvador de Bahía, considerándolas como espacio de resistencia y creación de lo común. Y el segundo objetivo es indagar sobre las posibilidades de descolonización de la educación en las escuelas, teniendo en cuenta la riqueza cultural de las favelas.

Los métodos de recolección de datos usados para este análisis fueron la observación participativa (que en algunos casos es investigación-acción) y más de 20 entrevistas semiestructuradas, realizadas de manera formal e informal.

En esta investigación se eligieron áreas que tienen una historia de participación en movimientos sociales y de resistencia, ya sea en temas locales, asuntos políticos, laborales o, en temas de derechos de las mujeres, y que también tienen tradiciones de rebeldía (Keisha-Khan, 2013). Así, se eligieron los barrios Estrada das Barreiras (Cabula), Curuzu (Libertad) y San Martin (Fazenda Grande do Retiro), de Salvador de Bahía, para el trabajo de campo realizado durante un periodo de dos años (20182019) (véase figura 1). La investigación se centró en actores sociales organizados en grupos culturales autogestionados, tales como músicos y danzantes de los blocos de carnaval, poetas de saraus, mujeres activistas afrofeministas, un grupo de 
Figura 1. Salvador de Bahía. Zona de estudio

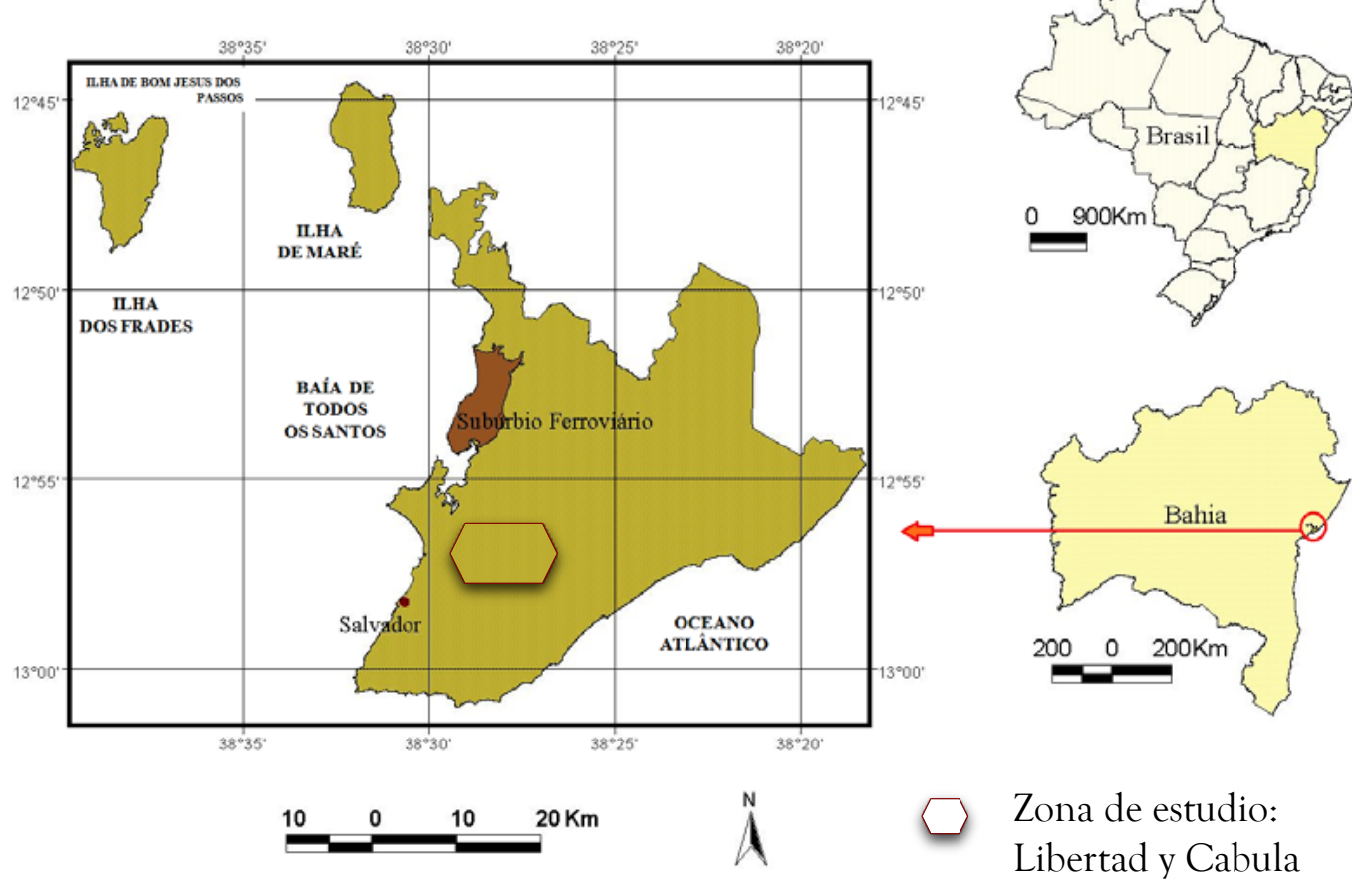

Fuente: adaptado de Ramos et al. (2013).

capoeira, así como educadores y estudiantes de escuelas y universidades públicas.

Es importante mencionar que, aunque no aparezcan en este artículo, también hacen parte de esta investigación algunas entrevistas hechas a descendientes de la comunidad Tupinambá, miembros de tres quilombos, ${ }^{3}$ actores activos del Movimiento de los Sin Tierra (MST) y de los Sin Techo de Salvador de Bahía (MSTB), participantes de una iglesia católica, asistentes de una iglesia protestante e integrantes de los yoruba - religiones candomblé y umbanda- - Lo anterior, para entender mejor los rasgos históricos de la cultura de resistencia en dicha ciudad.

\section{Tradición de rebeldía, culturas populares y generación de identidad rebelde como respuesta a la sociedad biopolítica}

Este análisis se inscribe en la actual corriente anticolonial (Porto-Conçalves, 2009; Quijano, 2000; Nascimento, 2019; Mansilla \& Ojeda, 2020), la cual plantea que "los conceptos de los estudios urbanos son insuficientes para abordar
${ }^{3}$ Comunidades autónomas afro-brasileñas equivalentes de Palenques en otros paises de Abya-YalaAfro-América. Véase Nascimento (2019). 
4 Véase Bajtín (2003) y Petropoulou (2014).

\section{territorias 44 Especial} 184 la transformación ontológica del suelo/ territorio" (Mansilla \& Ojeda, 2020, p. 1). Desde esa perspectiva, el presente documento se acerca a la noción de favela, nombre que se le ha dado a los barrios de autoconstrucción popular en Brasil. En cada ciudad, estos barrios periféricos han sido construidos por los habitantes del territorio periurbano a través de múltiples maneras y procesos, defendiendo el "derecho a la ciudad" (Lefebvre, 1968). Los paisajes reflejan sus historias e inspiran una poética urbana y de resistencia que sigue existiendo dentro de los siglos de diferentes maneras (Petropoulou, 2014). Ahora bien, siguiendo a Joselito Teles dos Santos (2018) y Stathis Damianakos (2003), se puede decir que las culturas rebeldes populares están en capacidad de contestar los habitus dominantes (Bourdieu, 2005; Wacquant, 2016; Petropoulou, 2020), construir identidades mestizas rebeldes de interseccionalidad (Anzaldua, 1987; Belausteguigoitia, 2009) y provocar "fracturas" en el sistema hegemónico, de forma que es posible ver por fuera del mismo (Holloway, 2010).

Estas clases se relacionan con los estratos sociales oprimidos que han sido marginados y traen prácticas culturales diferentes de los estratos dominantes, hábitos que son rebeldes y peligrosos para el sistema social que domina. Sus prácticas diarias están relacionadas con grabaciones en el "inconsciente colectivo" de levantamientos anteriores contra los explotadores, tienen la fuerza de la esperanza de liberación de los habitus que incorporan la explotación y el miedo como algo natural para los oprimidos, como lo explica muy bien Paulo Freire (1987). ${ }^{4}$

La "tradición de rebeldía" ha influido en la música, la danza y otras artes nacidas en los barrios de escasos recursos de las ciudades, como el rebetiko en Grecia, el fando en Portugal, el tango en Argentina y Uruguay, el blues en los Estados Unidos, el reggae en Jamaica y la samba y arte-marcial de capoeira en Brasil. Las corrientes de música moderna que ahora se despliegan en barrios populares en los distritos de la ciudad, como el rap, el hip hop, entre otros, también llevan evidencia de revueltas. Petropoulou (2020, p. 715) señala que: "[...] como la fiesta era también una herramienta de resistencia, el derecho a la ciudad venía junto con el derecho a la fiesta produciendo una tradición de rebeldía".

James Scott (1990) en su obra Los dominados y el arte de la resistencia, explora los límites entre la derrota de los insurgentes y los elementos culturales que se refieren a una rebelión que atraviesa el carnaval y otros eventos culturales heréticos permitidos solo para algunas fechas. Argumenta que estos elementos preparan al mundo para futuros levantamientos y no es solo la integración de la insurrección en el sistema a través de la celebración. Más adelante, Enrique Rajchenberg (2015, p. 47) compara las aproximaciones teóricas de Hobsbawm y Scott con la invisibilidad 
de la insurrección zapatista entre 1984 y 1994 diciendo que:

la idea de que la complacencia popular era únicamente una manera silenciosa y pública de ocultar la resistencia, constituyó un soporte teórico fuerte para quienes no concebían que en un mundo cada vez más injusto las luchas se hubieran interrumpido definitivamente. Podían ser sordas, ser invisibles a los ojos del poder o ser confinadas por este al ámbito de un bandidismo finisecular, pero proseguían al fin.

Es así como la rebeldía cotidiana y silenciosa resiste a la biopolítica de seguridad y genera identidades rebeldes. Refiriéndose a las tradiciones indígenas de resistencia en México, Luis Villoro $(1950 ; 2007)$ explica que la tradición - a diferencia de las culturas dominantes - no solo tiene elementos conservadores sino también insurreccionales que a menudo se mantienen ocultos. En este caso, la acción artística puede, en última instancia, actuar como una "pedagogía de la resistencia" (Freire, 2015) o como "edu-comunicación" (Schaun, 2002). Los movimientos sociales urbanos y regionales (Castells, 1983; Petropoulou, 2016) tienen un papel importante dentro de este proceso que finalmente puede cambiar el habitus de obediencia y subordinación con otros habitus silenciosos y rebeldes (Petropoulou, 2020).

En el caso de las favelas de Salvador de Bahía estudiadas en este artículo, se habla más de interculturalidad que de multiculturalidad ${ }^{5}$ con fuertes elementos culturales afrodescendientes - culto de las orishas: candomble, capoeira, comida y ropa típica, entre otras- que dialogan con culturas indígenas y europeas subalternas.

\section{Breve historia de la riqueza cultural de los barrios (favelas) de Salvador de Bahía y el proceso de su criminalización dentro de un contexto de desarrollo urbano desigual en contexto biopolítico}

En la actualidad, varios trabajos, entre los que se encuentran los estudios sobre desarrollo urbano de Salvador de Bahía (Vasconcelos, 2016; Andrade \& Brandão, 2009; Souza, 2001), ven las favelas como producto de la rápida urbanización, del éxodo rural o del exponencial crecimiento interno de la ciudad por medio de invenciones y de políticas de abandono a las clases sociales con más incidencia de pobreza. Sin embargo, son pocos los análisis que ponen en cuestión la construcción social de las favelas y sus estereotipos (Valladares, 2005; Deffner, 2010), así como los que se interesan en las culturas que sobresalen en estos barrios (Zaluar \& Alvito, 2006; Santos, 1975). Ni qué decir sobre la poca atención en los vínculos que tienen las favelas con las oprimidas culturas afro-indio-americanas (Carril, 2006; Campos, 2010) y los vastos conocimientos que reciben de ellas (Silva et al., 2009; Silva, 2011). En este
${ }^{5}$ Sobre interculturalidad, véase también a Santos y Carvalho (1997). 
${ }^{6}$ El autor tiene una postura de "élite blanca" que puede ser muy criticada, pero eso no niega las informaciones que se presentan aqui, las cuales confirman la perspectiva que tenían los académicos autoritarios frente a las sublevaciones de los negros afrodescendientes.

\section{territorias 44 Especial} 186 orden de ideas, pocos estudios critican la represión biopolítica aplicada en los territorios nombrados (Haesbaert, 2014; Håndlykken-Luz, 2019) y mucho menos a Salvador de Bahía (Keisha-Khan, 2013).

Según los datos oficiales del censo de Brasil del 2010, en las favelas viven 11,4 millones de personas, es decir, el $6 \%$ del total de la población. Vale destacar que, aparte de los bajos indicadores económicos, educativos y de salud, estos barrios también tienen como característica fundamental la riqueza de su diversidad sociocultural. Según Silva et al. (2009) y Gerardo Silva (2011), estos son, en algunas ocasiones, espacios de resistencia. De hecho, el caso de Salvador de Bahía es un ejemplo típico de las maneras en las que las tradiciones de rebeldía influyen en las culturas populares y en la formación de la ciudad.

La cultura nacida en este territorio, ignorada durante muchos años en las escuelas, tiene sus raíces en las insurrecciones de los nativos Tupinambá y de los pueblos subsaharianos esclavizados (revuelta de los Búzios de 1798 y de los Males de 1835), así como de sus descendientes afrobrasileños (Reis, 1995). De igual manera, está profundamente arraigada en las tradiciones de autonomía y resistencia de los quilombos de Cabula y de Urubu en Salvador de Bahía y del quilombo de Palmares en Alagoas (15101710). Finalmente, también se alimenta del movimiento panafricanista y del Partido de las Panteras Negras de los Estados
Unidos. Lo anterior ha contribuido a que después de 1978 renaciera el Movimiento Negro Unificado en Brasil (MNU), el cual ha estado muy presente en el Estado de Bahía, especialmente durante la dictadura militar y el periodo después de esta (MNU, 1998; García, 2008; J. Santos, 2018). En la década de los setenta, emergió una importante producción académica que se ha especializado en estudiar y denunciar las desigualdades étnico-raciales en Brasil, las cuales inciden negativamente, y de modo casi exclusivo, en las poblaciones negras e indígenas del país (Hasenbalg \& Silva, 1991; Silva, 2003; Queiroz, 2002).

Los levantamientos afrobrasileños dejaron huellas de resistencia que se pueden distinguir hasta ahora en la comida, la ropa (de color blanco, collares), y actualmente, en los llamados saraus (círculos de manifestaciones y expresiones poéticas, artísticas, entre otras, que puede haber comenzado por círculos de intelectuales, pero hoy, ha favorecido a las favelas) que alimentan la música rap y hip hop con versos de protesta política. La música, la danza (samba de roda, fugido nego, batucada, etcétera), la capoeira, las artes visuales, el teatro de calle, el teatro de los oprimidos y la literatura negra e indígena, son solo algunas expresiones de cultura de resistencia.

Luiz Vianna Filho ${ }^{6}(1946 / 2008$, pp. 135-136) cita Nina Rodrigues, quien dice:

el culto de gege-nago, que resistió a la conversión católica de los chicotes a las 
"fazentas" (fincas) y las plantaciones, que sobrevivió a todas las violencias de los señores a los esclavos, que ahora se observó de catolicismo de los blancos, está destinado a resistir por largo plazo, a la propaganda de las empresas y a las violencias de la policía.

Esta era una de las maneras en que los pueblos esclavizados permanecían en una actitud constante de rebelión e insumisión. Pero la más importante de las resistencias culturales viene de los quilombos - comunidades autónomas de pueblos esclavizados fugitivos-donde se desarrolló la samba de ronda (Nascimento, 2019; J. Santos 2018; Rejane, 2019).

En ese marco, Lira Neto (2017) explica que la samba carioca nació al inicio del siglo Xx a partir de una adaptación de la samba rural de Recôncavo Bahiano (descendente de las batidas afrobrasileiras), al ambiente urbano de Río de Janeiro y gracias a los nuevos medios de grabación se difundió en 1920 fuera del país.

Esta historia de resistencia (Alberti \& Pereira, 2016) se alimentó del movimiento panafricanista y los Panteras Negras de los Estados Unidos, quienes contribuyeron al renacimiento del Movimiento Negro Unificado en Brasil después 1978 que era muy presente en el Estado de la Bahía (MNU, 1988). - Cabe destacar que este periodo era dentro de la dictadura-. Dice Jaime (un anónimo entrevistado) que "en este periodo era muy difícil hablar de derechos, teniendo en cuenta que cada iniciativa de resistencia se trataba de cosa de comunistas y se castigaba a cárcel, exilio o muerte" (anónimo, comunicación personal, 2019).

Después de la dictadura, durante los gobiernos de Lula da Silva (2003-2011) y Roussef (2011-2016), se observaron cambios socioeconómicos importantes en el ámbito de bienestar y crecimiento de la clase media, no obstante, las desigualdades se establecieron a nivel socio-espacial. Como señalan los trabajos del Centro de Estudos dos Povos Afro-indio Americanos (CEPAIA): "Los efectos de la desigualdad étnico-racial, están incidiendo, negativamente, y de modo casi exclusivo, sobre las poblaciones negras e indígenas" (CEPAIA, 2011, p. 2). Una condición que se reproduce en cualquier indicador social, como la posesión de bienes duraderos y la evolución de la escolarización media a lo largo del siglo Xx (Instituto de Pesquisa Econômica Aplicada, IPEA, 2011; CEPAIA, 2011).

Según los datos del mapa de violencia por armas de fuego (Waiselfisz, 2016), en Brasil, entre el 2003 y el 2014, el número de personas negras asesinadas en esta modalidad creció un $46,9 \%$ pasando de 20291 a 29813 casos, la mayoría de ellos no llevados a juicio y que tienen por víctimas a jóvenes; mientras tanto, el número de casos de personas blancas disminuyó un 26,1 \%, pasó de 13224 a 9766 víctimas.

Según el Foro Brasileño de Seguridad Pública y el Atlas de Violencia 2019, entre el 2007 y el 2017 los homicidios hacia personas negras crecieron un $33,1 \%$, frente a los realizados en contra de personas territarias 44 Especial 187 


\section{territorias} 44 Especial blancas, los cuales se incrementaron en un 3,3\%. Entre otros datos, el $66 \%$ de mujeres asesinadas en el 2017 eran negras.

Desde el 2002, con la implantación del sistema de reserva de vacantes para los candidatos negros (Mattos, 2003), y posteriormente, en el 2007, para las poblaciones indígenas, la Universidad del Estado de Bahía (UNEB) inició el desarrollo de la modalidad de política de acción afirmativa. Aun cuando este sistema está dando sus primeros frutos - nuevos trabajos académicos desde un punto de vista descolonizado, pero con escasos ejemplos de nuevos profesores provenientes de sectores populares negros e indígenas-, el campo de la educación sigue siendo muy rígido y no ha podido reconocer e introducir en su matrícula la riqueza cultural de estos sectores.

Con el actual gobierno, la situación se agrava aún más. Según los datos de la estadística oficial, el $54,9 \%$ de la población de Brasil, - $51 \%$ en el censo del 2010 (IPEA, 2011) - está conformada por "negros y pardos", de los cuales el $75 \%$ está en situación de pobreza y solo el $17,8 \%$ entra en la clase media y mediaalta (CEPAIA, 2019). Asimismo, siguiendo los datos publicados por CEPAIA-UAEB, el $82,6 \%$ de las personas negras del Brasil afirman que el color de piel incide en la vida profesional. De hecho, vale destacar que el 9,9\% de este sector es analfabeto, lo cual corresponde al doble de la cifra de analfabetos blancos, que es de $4,2 \%$. Sumado a lo anterior, el $63,8 \%$ de niños negros de cinco a siete años trabaja, siendo que el tiempo medio de estudios para los blancos es de 10,3 años, mientras que para los negros es de 8,7 años. Finalmente, solo el $2 \%$ de este sector oprimido logra entrar a instituciones de educación superior (CEPAIA, 2019).

Siguiendo a Bomfim y Correira, los actores sociales de las favelas revelan la vida en comunidad inserta en un juego de contradicciones (Bomfim \& Correira, 2016). Los autores, estudiando la "educación geográfica" desarrollada en estos sectores de Salvador de Bahía, señalan que la espacialidad de dichos barrios está compuesta por diferentes tipos de lugares, que son estructurados por actos socio-simbólicos, afectivos o estéticos de interpretación de los alumnos. Tal estructura proporciona la base para el conocimiento y el juicio de valores dado a las interacciones sociales y a los problemas socioeconómicos y ambientales. Los denominados "polo positivo" y "polo negativo" de estos juicios constituyen una tensión socio-espacial entre la inserción y la marginación, las cuales están ligadas y conciliadas por medio de atributos simbólicos. En ese marco, Bomfim y Correira exponen:

La representación social del espacio de la favela, definida como un conjunto de símbolos, se inserta en las dimensiones estéticas, afectivas y socio-simbólicas construidas a través de las relaciones y posiciones de los estudiantes con los lugares característicos de estos barrios; esta 
se transforma y se organiza como conocimiento estructurado por las relaciones interactivas que los estudiantes tienen con el espacio real de la favela, constituyendo así la base cognitiva de las representaciones (2016, p. 8).

Considerando el contexto descrito, este trabajo intenta investigar las posibilidades de descolonización de la educación en las escuelas, teniendo en cuenta la sistemáticamente negada y criminalizada riqueza cultural de las favelas, ligada a un desarrollo urbano desigual y a unas biothánato-políticas coloniales (Haesbaert, 2014).

En este sentido, es necesario identificar la problemática de la racialización como elemento estructurante en los procesos de criminalización de las poblaciones favelares, sus identidades y culturas. Así, el predominio de la cultura colonial — que se presenta como cultura europea o cultura de las élites "blancas" - en detrimento de la cultura "negra" — afrodescendiente, indígena, mestiza y popular-, la sobrevaloración de la población "blanca" por la deshumanización y objetivación de la población "negra" transformándola en cuerpos desechables de homo sacer (Agamben, 1998), es un elemento a debatir de forma urgente dentro de las escuelas, con el fin de identificar estrategias racistas y desmantelar sus estructuras.

Por una parte, Arouca (2017) llama la atención sobre el hecho de que algunos jóvenes de las comunidades de favelas identifican elementos de su propia estética (vestimenta, corte de pelo, lenguaje oral y corporal) como si fueran propios de "ladrón"; sin embargo, tales elementos son identidad de gran parte de la población joven de estos lugares. Roberto Marques (2013) explica que estas prácticas de discriminación están ligadas a políticas coloniales presentes en todos los niveles de las instituciones. Asimismo, durante los grupos focales realizados en su investigación, Arouca (2017) identificó que los docentes dentro del aula reconocen los elementos de identidad de los estudiantes con respeto, dialogando a través de los símbolos y códigos que traen de una manera positiva. El reflejo de esta identificación está en su interés por las clases. Por otra parte, se demostró que cuando los estudiantes ven sus símbolos y códigos marginados y estigmatizados por los profesores, aumenta el riesgo de deserción escolar.

Además, es importante señalar que la criminalización de la población negra y de la favela que está presente en las escuelas es una reproducción del contexto social, al que son sometidos los jóvenes negros de este sector. Así, por ejemplo, están excluidos de derechos básicos como el acceso al ocio (leisure). En este caso, la población joven de la favela ve sus eventos de socialización tratados como una reunión de delincuentes, a menudo siendo combatidos ostensible y violentamente por la policía. Estas prácticas tienen sus raíces en las representaciones negativas y territarios 44 Especial 189 


\section{territorias} 44 Especial racializadas de la sociedad, que ve un problema en la favela, el lugar de la pobreza, la violencia y la desesperanza. Lecturas que se reproducen tanto fuera como dentro de la propia favela tienen su origen en la historia de Brasil, en la forma en que se crearon las favelas: ¡A través de políticas excluyentes, marginales, degradantes y deshumanizadoras! En la siguiente sección se desarrollará este tema.

\section{El origen de las favelas, barrios de autoconstrucción popular}

La historia de los barrios de autoconstrucción popular en Brasil está marcada por la exclusión estatal de las poblaciones en situación de pobreza. Souza y Silva denuncian los procesos económicos y políticos que han marginado a estos sectores, relegándolos a vivir en espacios no estructurados y en condiciones inadecuadas (Souza, 2001; Souza, 2008; Silva, 2008). Silva argumenta que la Ley 1850 y el Estatuto 1964 de la Tierra, regularizan y legitiman las posesiones de los latifundistas (Silva, 2008). Estos siempre han representado un problema importante para que los sectores populares adquieran tierras, puesto que las han acumulado históricamente.

Siguiendo a Souza, con la Ley de la Tierra el capital inmobiliario comenzó a desempeñar un papel importante en los procesos de compra y venta de terrenos (Souza, 2001; Souza, 2008). Por lo tanto, el centro de la ciudad es más apreciado, lo que genera que las poblaciones de más escasos recursos se localicen en las periferias, estratificándose así el espacio de la ciudad. En este proceso, dichos sectores sin condiciones financieras para comprar tierras o casas, tomaron como alternativa ubicarse en lugares distantes o "clandestinos" de barrios marginales que no tienen la infraestructura necesaria.

En la formación del Estado Nuevo, el régimen brasilero empezó a buscar alternativas al problema de crisis de vivienda del país. En este periodo se crearon los Institutos de Jubilación y Bienestar (IAP), una iniciativa dirigida únicamente al público de trabajadores y funcionarios. Un año después de la finalización de este periodo, en 1946 se estableció el primer organismo nacional para combatir la crisis de la vivienda (Souza, 2001): la Fundación Popular House (FCP) (Decreto-Ley 9218 del 1 de mayo de 1946).

Esta iniciativa se extendió hasta la década de los sesenta, en la que se creó el Banco Nacional de la Vivienda (BNH) (Ley 4380 de 1964). Esta política, llevada a cabo en sociedad con los grandes constructores y el capital inmobiliario, dejó fuera, una vez más, a las poblaciones más vulnerables. Lo anterior, debido a que consiste en la compra y construcción de viviendas según el rango salarial, mediante comprobante de ingresos con un valor de tres salarios mínimos. Precisamente, es hasta la década de los ochenta que el Estado comienza a invertir en infraestructura 
para mejorar los espacios de ocupaciones ilegales (Souza, 2008).

En medio de este contexto de exclusión y falta de asistencia, los sectores empobrecidos se unen para sobrevivir. De ese modo, la autoconstrucción se convierte en una alternativa necesaria para la población (Maricato, 1982). Las favelas, al igual que otros barrios de este tipo en la ocupación de espacios vacíos y en la construcción solidaria de las casas de los nuevos habitantes, se convierten en espacios de resistencia en los que, por medio de la solidaridad, se crea lo común (Petropoulou, 2018a).

Según Silva et al. (2009), en Brasil existen cinco perfiles que han definido desde diferentes campos a las favelas:

- El de autoconstrucción.

- El sociourbanístico, que las concibe como edificios construidos fuera de los estándares dictados por los planes urbanos estatales. Por ejemplo, en las estadísticas oficiales se les presenta como "entidades anormales". Estos polígonos representan solo el inicio de un barrio de autoconstrucción popular y, no los barrios consolidados que siguen con problemas estructurales.

- El sociopolítico, que las entiende como espacios desprovistos de políticas públicas y acciones estatales.

- El socioeconómico, que las ve como territorios precarios en el mercado formal, en especial, el financiero, inmobiliario y de servicios.
- El sociocultural, que muestra su gran diversidad cultural, así como la presencia de población negra o indígena según la región en la que se encuentra la comunidad. Esta perspectiva intercultural está en diálogo con las tradiciones de resistencia y creatividad de las favelas.

La constante expansión y densificación de estos espacios está relacionada con las dificultades de acceso que tienen los sectores empobrecidos de la población a la propiedad de la vivienda en otros lugares de las ciudades. Precisamente, el Instituto Brasileño de Geografía y Estadística (IBGE) señala algunas características de las favelas que aportan a esta situación, tales como el poco espacio que hay entre las estructuras de las casas y la elevación vertical de los pisos (IBGE, 2013).

No obstante, también existen factores culturales, comunicativos y de protección, en la manera laberíntica en la que están construidos estos barrios. Se puede mencionar, que la mayoría de la población que habita las favelas es joven, afrodescendiente y en estado de pobreza, aunque vale aclarar que estas características las tienen la mayoría de brasileños (IBGE, 2013). En las favelas se emplazan los sectores urbanos excluidos de las políticas públicas y que son invisibles para el capital inmobiliario. 


\section{Desarrollo urbano, estructura socio-espacial y educación en la Región Metropolitana de Salvador de Bahía}

Salvador de Bahía está situada en un espacio de litoral y de colinas habitadas por indígenas Tupinambá desde antes de 1549. Se constituye como primera capital de Brasil, gracias a su economía especulativa (comercio de diamantes y oro), basada en el uso de pueblos esclavizados (Prezia, 2017). En este marco se formó el quilombo de Cabula (destruido en 1807) en el norte de la ciudad, lugar de resistencia y autonomía de esclavos auto-liberados, lo que deja una importante tradición de rebeldía en los habitantes de la zona.

Después de la abolición de la esclavitud, la ciudad siguió siendo la metrópoli económica, política y administrativa de Brasil. Recibe diferentes productos importados de otras partes del país como caña de azúcar, cacao, café, tabaco, entre otros. Todo esto deja marcas importantes en su paisaje urbano, las cuales durarán hasta el siglo Xx (Santos, 1959/2008), cuando este comienza a cambiar con la integración del mercado nacional por vía terrestre con el petróleo del Recôncavo (1950) y con el proceso de industrialización en los años sesenta (Centro Industrial de Aratu, CIA, desde 1966) y setenta (Polo Petroquímico de Camaçari desde 1978), procesos que atraen población a la periferia urbana.

En este contexto, en 1973 se formó la Región Metropolitana de Salvador de
Bahía (RMS). Una salvedad muy importante, porque a partir de esta fecha empezó el desarrollo turístico de la ciudad, el cual se promocionó (branding) a través de la representación de una falsa reconciliación y mixtura entre culturas y religiones - por supuesto, esto no ocurrió-. De hecho, entre las décadas de los ochenta y los noventa, por medio de un cambio de uso de suelo y de una legislación selectiva de casas para expropiación, se expulsó de Pelurino a la periferia a una población empobrecida y en su mayoría negra, lo cual confirma un violento proceso de gentrificación del centro histórico de la ciudad (después de su nombramiento por la Unesco como patrimonio de la humanidad en 1985), con muchas resistencias hasta hoy (Nobre, 2002; Zanirato, 2004; CEPAIA, 2015, Garmany \& Richmod, 2020).

De acuerdo a diferentes autores, el desarrollo urbano de este territorio se caracteriza por la segregación socio-espacial, la cual tiene sus raíces en la exclusión histórica bio-thánato-política de ciertas poblaciones. Analizando los mapas y los textos de Carvalho y Pereira, se puede observar que entre 1991 y el 2010 las áreas de la ciudad catalogadas como clase media alta se concentran en la orilla de la ciudad, donde se multiplican los condominios cerrados (Carvalho \& Pereira, 2014). A ellas se unen otras zonas, ubicadas en barrios antiguos cercanos al centro tradicional, que pasan de ser clase media a clase media alta, de acuerdo con 
procesos de gentrificación y construcción de nuevas edificaciones.

Por otro lado, en las áreas populares (favelas y otras) donde se aglomeran las poblaciones afrodescendientes y las más empobrecidas de la ciudad, la evolución ha sido más diversa. Algunas partes de los barrios más antiguos como Libertad, Ciudad Baja y Cajazeiras, están habitadas por personas de un nivel socioeconómico un poco más elevado, lo que puede deberse a un proceso interior - mejora en las condiciones de vida- o exterior migraciones internas-. No obstante, los barrios populares más lejanos o ligados a la producción industrial y portuaria como Plataforma, Mata Oscura, Pau da Lima, Nordeste de Amaralina, Boca do Rio y Barrio de la Paz, experimentan una baja en sus condiciones de vida en medio de la crisis económica y del crecimiento del desempleo.

Como subrayan Carvalho y Pereira, el Plan Director de Desarrollo Urbano (PDDU) del 2004, orienta los intereses del mercado inmobiliario en la "zona noble" de la ciudad poblada por gente de altos ingresos (Carvalho \& Pereira, 2014). Además, a principios del 2010, el ayuntamiento lanzó mediante una fuerte campaña publicitaria, 22 proyectos relacionados con el denominado Plan Estratégico, propuesto en gran medida, por un grupo de empresas del sector inmobiliario. Este tiene un título inscrito en la lógica neoliberal de competencia internacional de las ciudades: Salvador Capital Mundial e incluye nuevas avenidas y viaductos, así como la recalificación de la Franja Marítima de la Ciudad Baja y la Península de Itapagipe. Este tipo de proyectos dejan a su suerte a las periferias populares donde se concentran las favelas, a excepción de algunos procesos de regularización urbanística realizados en barrios más centrales, producto de importantes luchas sociales de los habitantes (por ejemplo, Libertad).

En conclusión, el patrón ya consolidado en Salvador y Lauro de Freitas se expresa a través de dos movimientos espaciales. Por una parte, las clases sociales altas avanzan hacia el norte, por el litoral, y ocupan las áreas costeras expulsando poco a poco las comunas y quilombos de los sectores empobrecidos. Por otra, las clases populares avanzan hacia los municipios de Camaçari, Mata de São João y ocupan las áreas interiores de la ciudad. Al respecto, Carvalho y Pereira afirman:

la segregación, a su vez, ahora no se expresa solamente a través del patrón centro y periferia, pero cada vez más, toma la forma de enclaves en áreas no centrales o periféricas. Estos enclaves pueden ser de alta renta, como los condominios cerrados, que tienen escalas ahora mayores, o de bajos ingresos, como las invasiones o parcelas populares, $\mathrm{o}$ de media renta, como los emprendimientos del Programa Mi Casa Mi Vida, todos ellos empujando la metrópoli en una periferia segmentada y desigual (2014, p. 138). territarios 44 Especial 193 
En este marco se puede traer a discusión la relación entre desarrollo urbano, educación y producción en las favelas. Para ello, son fundamentales los abordajes y contribuciones que hace la geografía al campo de la educación, en tanto permiten presentar un análisis sobre la simultaneidad, tensiones, enfrentamientos, contradicciones y cambios que constituyen el tema de este artículo.

En el mapa de la figura 2 se evidencian importantes cifras sobre el abandono escolar en el Estado de Bahía. Vale destacar que en la Región Metropolitana de Salvador los porcentajes de analfabetismo son inferiores a los de las zonas rurales del Estado. Sin embargo, si se observa detalladamente el mapa, con polígonos más cercanos a los límites de los barrios de los sectores urbanos (Fernandes \& Carvalho, 2014; Souza, 2018), justo en las periferias donde están ubicadas las favelas, suben los niveles de abandono escolar.

Figura 2. Niveles de población 4-17 años no matriculada, en relación con la población total del Estado en Brasil (2010)

\section{tersitorios 44 Especial}

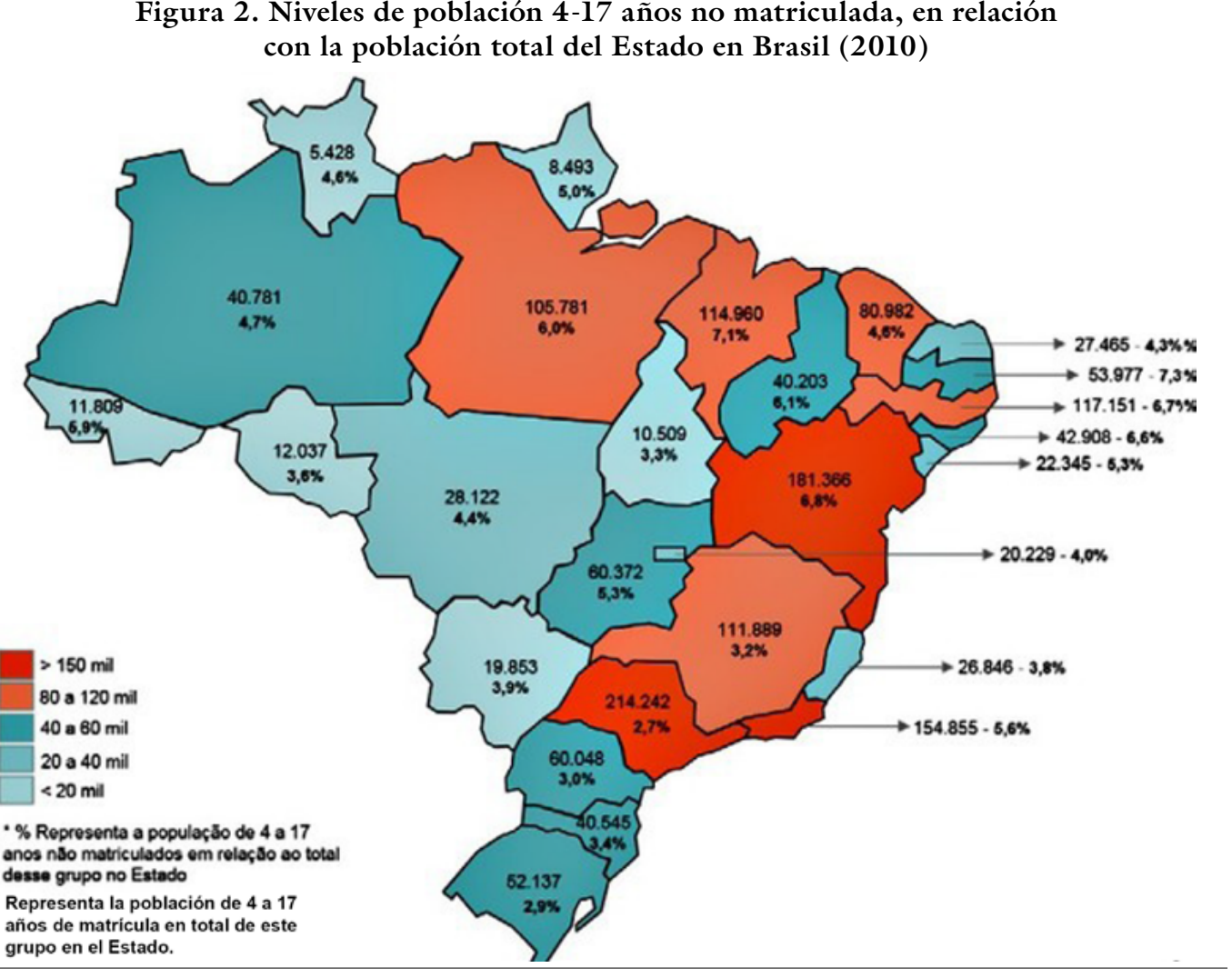

Fuente: Emilio Riguiera a partir de datos del censo del 2010. 
Según el Instituto Brasileño de Estadística y Geografía (IBGE), Bahía tiene más de 1,5 millones de analfabetos, de los cuales 61351 están en la ciudad de Salvador (IBGE, 2013). Estas personas — de 15 años en adelante-, no saben leer ni escribir, lo que significa que no han tenido acceso, o no han concluido la formación básica. Según el Informe Juventud y Políticas Públicas en Salvador-Bahía (UNFPA, 2013), 11000 jóvenes analfabetos se encuentran en situación de vulnerabilidad, la cual se constituye también por la precariedad de la infraestructura de sus viviendas y la dificultad en cuanto al acceso de bienes y servicios públicos.

\section{Culturas de rebeldía y descolonización de la educación}

Siguiendo los planteamientos de Paulo Freire, la educación es un medio para desarrollar el pensamiento crítico mediante la conciencia de la tríada opresión-libertademancipación (Freire, 1987; Freire, 2015). De esta forma, las personas reconocen su lugar como sujetos históricos y se asumen protagonistas de las luchas que tienen como propósito el fin de las opresiones existentes en la sociedad.

Actualmente, los estudiantes negros provenientes de barrios marginados son las mayores víctimas de discriminación en las instituciones educativas. De hecho, Arouca señala que el racismo presente en la rutina escolar no es un tema de discusión en las aulas de clase (Arouca, 2017).
Precisamente, durante una de las reuniones realizadas con el grupo focal de esta investigación, un estudiante fue catalogado como ladrón por ser negro y tener una estética común entre los jóvenes de los barrios populares de Salvador de Bahía. Al respecto, Sant'ana dice que al hablar

de discriminación étnico-racial en las escuelas, aparte del racismo institucional ciertamente estamos hablando de prácticas discriminatorias, prejuiciosas, que involucran un universo compuesto de relaciones raciales personales entre los estudiantes, profesores, dirección de la escuela, pero también el fuerte racismo repasado a través de los libros didácticos. Sin olvidar, sin embargo, el racismo institucional, reflejado a través de políticas educativas que afectan negativamente a los negros (Sant'ana, 2005 , p. 50$)$.

En consecuencia, es esencial que las escuelas generen medidas, acciones y proyectos para enfrentar el racismo en Brasil. Parte importante de ello es fomentar en las poblaciones de barrios mayoritariamente afrodescendientes, su reconocimiento como sujetos históricos capaces de promover un cambio positivo en sus contextos y, de luchar activamente por los derechos que el Estado les ha negado de forma sistemática, para mantener el poder de las élites esclavistas.

Entre algunas iniciativas, la vieja Legislación de Brasil (LDB) es alterada por la Ley 10.639 del 2003, en la cual se inserta territorias 44 Especial 195 
la obligatoriedad de la enseñanza de la historia y cultura afrobrasileña. Según esta Ley,

el plan de estudios mencionado en el título de este artículo incluirá el estudio de la Historia de África y de los africanos, la lucha de los negros en Brasil, la cultura negra en Brasil y los negros en la formación de la sociedad nacional, rescatando la contribución de los pueblos negros en las áreas sociales, económicas y políticas relevantes para la historia de Brasil (Ley 10.639, 2003, art. 26-A, par. 1, p. 21).

Todos los Estados Federales del país son llamados a aplicar dicha Ley. Bahía avanza en ello después de un amplio debate con diversas organizaciones del movimiento negro, lo que tiene como resultado el Estatuto de la Igualdad Racial (MPSP, 2014). En cuanto a la efectiva implementación de la Ley 10.639, esta no se ha dado aún. Sin embargo, según las entrevistas a educadores y educadoras, existen "acciones aisladas, por parte de las organizaciones, que propenden por la elaboración de proyectos que actúan puntualmente en las unidades de enseñanza" (comunicación personal, Enero 2019).

La Ley también manifiesta la necesidad de introducir en el programa escolar la historia de las favelas, pues allí se localizan los hogares de la mayoría de las comunidades negras brasileñas. Según Brandão (2006), la educación popular debe surgir de las demandas del contexto social en el que se desarrolla el proceso pedagógico. Así, las necesidades estructurales que surgen de la ausencia de políticas públicas deben estar en los planes de estudio de los proyectos educativos, para que sus participantes (gerentes, maestros y estudiantes) puedan reflexionar críticamente sobre estos temas, buscando alternativas y formas de superar los problemas de cada contexto específico.

Así mismo, Arroyo señala la importancia de incorporar elementos de las luchas sociales en la educación, para difundir una perspectiva que invite a la emancipación social (Arroyo, 2012). Esto permite generar y compartir saberes sobre las luchas históricas y los logros de los grupos sociales en la búsqueda por la equidad.

De otra parte, Ribeiro afirma que los grupos sociales marginados por el sistema social tienen un lugar privilegiado en la comprensión de la opresión y que, por ello, están en mejores condiciones de encontrar alternativas para superar los problemas que genera la desigualdad (Ribeiro, 2017). En esa línea, para Dowbor (2006) la gestión de proyectos educativos debe estar ligada a la participación de la comunidad escolar.

Todo esto lleva a reflexionar sobre los elementos que pueden contribuir a los procesos educativos desarrollados en las favelas. Arouca, después de una investigación en el barrio Estrada das Barreiras en Salvador de Bahía, defiende que dentro del currículo escolar se debe considerar la presencia de las diversas culturas que componen la comunidad educativa, teniendo en cuenta diferencias y similitudes, 
proponiendo diálogos e invitando a la comprensión y respeto entre estas (Arouca, 2017). De ese modo, es de gran relevancia implementar en los espacios educativos de las favelas, una perspectiva descolonizadora de la educación, que dé valor y legitimidad a los saberes de los oprimidos, enfrentando las lógicas hegemónicas que hipervalorizan unos grupos en detrimento de otros.

Las canciones, los lenguajes, los códigos socioculturales y las dimensiones estéticas, al igual que las especificidades geográficas, políticas y económicas, necesitan ser reconocidas afirmativamente como elementos identitarios de los sujetos y las comunidades que componen y localizan la escuela (Marques, 2013). Como dice Damianakos, no se trata de "un mosaico de culturas", sino de "un crisol de culturas" liberadoras, que pueden dar fuerza emancipatoria a los pueblos subalternos (Damianakos, 2003, p. 33).

Por consiguiente, los discursos y prácticas antirracistas son fundamentales para la pedagogía comunitaria, inscrita en la obra de Paulo Freire. En lo que respecta a una educación libertadora en las favelas de Salvador de Bahía, estudiadas en este artículo, aparece la noción de interculturalidad, no de multiculturalidad, resaltando especialmente la herencia afrodescendiente, en la que se enmarca por ejemplo el culto a los orishas candomble, capoeira, comida y ropa típica, entre otras, y su diálogo con el legado indígena y europeo.

Este panorama usualmente está fuera de las escuelas, en otras palabras, se ha ocultado e invisibilizado. Vale señalar que, históricamente, la escuela ha funcionado con un punto de vista bio-thánatopolítico con el propósito de “civilizar", "europeizar" y "castigar la espontaneidad", yendo en contra de la herencia intercultural de los otros, que son en gran medida los habitantes de las favelas. Estos barrios de autoconstrucción popular han sido discriminados durante muchos años por su carácter "desobediente", debido al peligro que este representa para las clases dominantes (Petropoulou, 2014).

El papel pedagógico de las actuales culturas populares es muy importante. Desde 1980, fuera del sector de la educación oficial, se han desarrollado nuevas iniciativas en la ciudad, tales como CIPó; Comunicación Interactiva, Foro de Arte y Cultura del SFS; Movimiento de Cultura Popular del SFs; Acervo de la losa; Cultucar; etcétera. Algunas de ellas contribuyen al desarrollo de otro tipo de educación, que recibe fuertes influencias de las tradiciones de rebeldía y solidaridad.

Así, han ido emergiendo en Salvador grupos de educación musical, dancística, poética, plástica, en capoeira, entre otras, con visibles filiaciones políticas. Este es el caso del Araketu, en el barrio Peri Peri; de la asociación Para Catu, Timbalada y el Sarau do Braun (Carlinhos Brown), en Candeal; del Bloco OLODUM (2005), en Pelurino; y de las escuelas relacionadas con el Bloco Ilê Aiyê, el Bloco Mudança de Garcia y otros (Schaun, 2002). territarios 44 Especial 197 
${ }^{7}$ Estos blocos de indio se refieren a las grandes luchas de los indigenas Apaches en los Estados Unidos y a los quilombos afro-indigenas de Brasil. En esta medida, se pueden considerar como glocales.

${ }^{8}$ Canto divulgado por Gilberto Gil-LP Refavela.

${ }^{9}$ Dicha práctica es común de la cultura de rebeldia en la historia mundial, por ejemplo, en los carnavales afrodescendientes de Notting Hill en Londres, a finales del siglo XIX (Riggio, 2004), de Montevideo, Arica, Oruro y otros (Ardito, 2014) y en los carnavales afro-indigenas de Nueva Orleans, Barranquilla, Rio de Janeiro, Recife y otros (Lizcano \& González, 2018). Todos denunciaban el racismo y tenian una tradición de rebeldía llevada de los esclavizados africanos fúgidos (establecidos en comunidades autónomas de Palenques y Quilombos) a veces mezclada con tradiciones rebeldes de comunidades indigenas.

\section{territarias 44 Especial} 198
Vale resaltar que el Bloco Ilê Aiyê, situado en el barrio Curuzu, emprende un Proyecto de Extensión Pedagógica que incluye varias iniciativas. Entre ellas están: la Escuela Mãe Hilda (1995), con más de dos mil alumnos; la Escuela de Percusión Band'erê; la Escuela de Profesionalización; y un espacio cultural en el único edificio del barrio dedicado a actividades de este tipo.

En 1974 se creó este bloco, cuya música es "una fusión de samba tocada en las antiguas escuelas de samba e blocos de indio $^{7}$ de Salvador, aliada al toque sagrado de candomble" (Ilê Aiyê, 2019, p. 1), la cual empieza un trabajo de concienciación sobre la fuerza negra (MNU, 1988; Afolabi, 2016). Ilê Aiyê, en yoruba, se puede traducir al español como "mundo negro" o, de forma más literal, "casa de este mundo" (Ilê Aiyê, 2019). Entre sus cantos está una historia que dice: "Somos crioulo doido, somos bem legal, temos cabelo duro, somos black PAU [...]". ${ }^{8}$

Teniendo en cuenta que el carnaval oficial es un evento comercial cargado de una historia de segregación racial-social, su reafricanización es una acción de resistencia creativa. Osmundo de Araújo Pinho expone que "esta reafricanización del carnaval de Bahía, producida por Ilê Aiyê, reproduce nuevas identidades raciales/ sociales colectivas, nuevas subjetividades interseccionales de tradición afrodescendiente y de cultura de consumo y nuevas posiciones de sujeto afrodescendiente sustentadas en discursos de "resistencia""
(Ilê Aiyê, 2019, p. 4). La decisión de crear un bloco de "poder negro" (black power) dentro de la dictadura militar era un acto radical $^{9}$ que denunciaba el falso discurso nacional sobre la inexistencia de segregación racial en Brasil (Ardito, 2014).

Las iniciativas mencionadas se fortalecen durante los primeros años del Gobierno de Lula y con la Ley 10.639 del 2003 de Incentivo a la Cultura. La mayoría se institucionaliza con esto, al tiempo que guarda sus principios fundadores e intenta ampliar sus propósitos con el enfoque de género y la perspectiva de educación intercultural.

La investigación de la cual nace este artículo, muestra que a partir del 2010 surgen otros colectivos independientes que trabajan a través de asambleas abiertas, construyen la autonomía en la vida cotidiana e intentan crear una conciencia antipatriarcal, antirracista y anticapitalista, inspirándose en los quilombos. En este orden de ideas, ofrecen otra educación participativa, en la cual, la premisa es dar lugar a mundos donde quepan muchos otros mundos.

Esta nueva ola de movimientos, que tiene un tipo de organización horizontal, empieza en 1981 con la Quebra-quebra Bahía, una revuelta popular contra el aumento del precio de transportes, en la que se ocupa la ciudad durante 14 días (Fereira, 2008). Asimismo, las insurrecciones contra las políticas de segregación que se instauran antes del Mundial de Fútbol y los Juegos Olímpicos del periodo 
2013-2014, alimentaron nuevas iniciativas culturales y políticas en Salvador, aunque al mismo tiempo se realizan nuevas intervenciones militares en las favelas. ${ }^{10}$

Para el 2018, en un mapeo sobre los conflictos y resistencias vinculadas a las luchas por la tierra en el Estado de Bahía, llevado a cabo por el grupo de investigación CARTOGRAFAR, se registran más de 3030 puntos de conflicto y 20125 áreas recuperadas (ocupadas), tales como quilombos, comunidades indígenas, colonos asociados, reforma agraria, campamentos, espacios autónomos de pasto y de pescadores, crédito fundario, cédula de tierra y otros (Brumarinho, 2019).

En dicho contexto, al interior de los barrios periféricos (favelas) se desarrollan nuevas prácticas de resistencia cultural: los denominados saraus, encuentros libres de poesía, música y prosa; los teatros populares como el teatro del oprimido; los grupos de capoeira; los grupos musicales de rap, hip hop, reggae, ska rebelde; y el grafitimural. Todas estas prácticas propician nuevos encuentros culturales, políticos y antirracistas entre los jóvenes.

Según las entrevistas y el trabajo de investigación participativa realizado, estos nuevos espacios tienen un carácter horizontal, sobre todo, en lo que respecta a la toma de decisiones, la cual se realiza mediante asambleas abiertas o semiabiertas. De igual forma, estos espacios se reproducen de manera rizomática, siguiendo las luchas del movimiento negro independiente y el de los indígenas.
Además, les ofrecen, precisamente, nuevas perspectivas antipatriarcales y anticapitalistas. Por todo lo dicho, se puede hablar de una nueva ola de cultura popular, con tradición de rebeldía, e interseccionalidad (Collins, 2000).

Por ejemplo, el Sarau da Onça, en la Quebrada de Salvador, reúne más de 50 escritores y más de 500 participantes. Este Sarau, que da una formación artística, política e identitaria, se inspira en la revuelta de los Búzios en 1798 y de los Males en 1835, en las luchas de los quilombos Palmares y Urubú y en la tradición de los Poetas de Praça de los años ochenta en Salvador; también tiene como referencia al Sarau Bem Blak de barrio/ favela Cooperifa, en el Sur de São Paulo. Finalmente, se enlaza a los barrios de autoconstrucción popular de Sussuarana, Cabula, Lobato y Vila Moyses, en los cuales se habla por medio de la poesía sobre los asesinatos cometidos por la policía en estos territorios (y la intervención militar a Cabula en el 2015), así como sobre la injusticia social y el racismo que se vive en la cotidianidad (Sarau da Onça, 2017; Sarau da Onça, 2019).

Los colectivos, movimientos y agrupaciones nombradas tienen una característica en común: intentan crear nuevos mundos de una manera horizontal y abierta, rebelándose y resistiendo a la cultura dominante capitalista, machista y racista. Como dicen Alex y Emerson (2018) del espacio autogestivo de Capoeira Olorum:
${ }^{10}$ Véase carta escrita sobre Negro Blul asesinado por la policía militar el $2 / 6 / 2015 ; y 13$ asesinados por el asesinato de Hamilton Borges, Coordinador de la "Campana React or Be Dead". https://www.bnews.com. br/noticias/principal/ cidades/108385,jovensmortos-no-cabula-sao-bomenageadas-durante-sarau-neste-sabado-jovensmorto.html

\section{territarios 44 Especial 199}




\section{territorias} 44 Especial
Capoeira es una filosofía de vida. ¡Es mágica! ¡Abre tantas puertas! Tantos artistas, percusionistas salen de capoeira. ¿¿sta magia no viene del barrio? Sí, con una dificultad tan grande. Es como cuando vas a tallar algo en bruto, que poco a poco toma la forma de una escultura. Es un proceso mágico. La relación que se construye dentro de capoeira entre la gente es mágica. Eso no se ve, no se oye, pero viene un momento en que sientes que ya puedes salir. La dinámica del grupo a veces no se puede explicar cómo se hace, pero es mágica, es superior de lo que hacemos cada uno por separado.

Estas iniciativas culturales tienen referencias territoriales y están muy enraizadas en la periferia afrodescendiente de la ciudad, en otras palabras, en las denominadas favelas. Estas formas de urbanización -barrios de autoconstrucción popular(Petropoulou, 2019), la producción social del espacio urbano mediante este tipo de asentamientos, y su crecimiento, están ligados a la historia colonial de la denominada "élite do atraso" (Souza, 2018) y al modo de desarrollo capitalista de la ciudad de Salvador de Bahía (Santos, 1959/2008).

Esto se reproduce actualmente bajo diferentes formas y a través de algunos actores políticos que sirven a las clases dominantes. Por ejemplo, algunos miembros de iglesias protestantes insisten en la negación de las culturas populares afrodescendientes, indígenas y de liberación sexual, así como los grandes comerciantes de narcóticos reproducen lógicas y estereotipos heterosexistas. Entonces, se puede hablar de una situación de habitus contestado (Petropoulou, 2020) entre diferentes culturas de vida. El asesinato de Mestre de Capoeira Moa Do Katende el 8 de octubre del 2018, es uno de los ejemplos de habitus contestado y de la represión política y racista en el centro histórico.

En los últimos años, algunos elementos de la cultura popular han sido fragmentados y estilizados, lo que ha permitido su ingreso y reconocimiento en las escuelas y en campos artísticos como el musical. Lo mismo ha ocurrido en términos urbanos, siendo que algunos lugares como Pelurino, se han convertido en devastadores centros turísticos y gentrificados (CEPAIA, 2015).

Esto quiere decir que dichos elementos han sido adaptados a los intereses culturales hegemónicos. Mientras esta comercialización de la cultura popular se reproduce en el centro histórico, la estigmatización, la discriminación y el conflicto siguen presentes en las favelas, que son los lugares de donde proviene esta cultura. Lo anterior significa que la tradición de rebeldía de sus habitantes no se respeta y es usada como elemento de museo folclórico creado desde un punto de vista elitista, es decir, como algo inferior o algo histórico que ya no existe (algo muerto, no vivo).

Como es usual en las sociedades capitalistas neoliberales de bio-thánato-políticas, la producción de plusvalía conlleva el paso de ciertos productos, pero no el de quienes 
los producen. La única diferencia es que en la ciudad de Salvador, las fronteras y los habitus han sido contestados históricamente, desde el nacimiento de la ciudad.

\section{Conclusiones y perspectivas}

En este análisis se da una perspectiva sobre la realidad de la juventud brasilera localizada en la ciudad de Salvador de Bahía, concentrada en las favelas de Libertad y Cabula, la cual está vinculada con las políticas de exclusión socio-espacial y de desarrollo urbano selectivo. De igual manera, se subraya la tradición de rebeldía y la producción cultural de la periferia urbana en este territorio, que tiene por actores a los colectivos de jóvenes que imprimen sus visiones socioculturales en diversos espacios educativos, tanto formales como no formales.

Desde estas prácticas se facilita el desarrollo y la participación social, cultural y política de los habitantes de estos barrios, quienes obtienen herramientas para transformar su realidad. En este sentido, las favelas se convierten en espacios de resistencia y creación de lo común.

El caso de Salvador de Bahía es un ejemplo típico de la llamada "educación prohibida" (REEVO, 2016), que precisamente alude a la construcción de espacios para la creación de lo común. Aquí es importante resaltar la necesidad de desarrollar perspectivas educativas que contemplen las especificidades históricas y culturales de las comunidades de las favelas.

Los resultados de la investigación, muestran que la multiplicidad de culturas populares desarrolladas en las favelas tiene una fuerte relación con la tradición de rebeldía afro-indígena y popular de Brasil. Esto se expresa en los variados encuentros culturales dentro de los barrios, los cuales son poco o nada mencionados en las noticias, ya que estas prefieren estigmatizarles y presentarles como espacios de delincuencia y peligro.

Este trabajo confirma que los elementos importantes en la constitución de las favelas no son tenidos en cuenta en la escuela: el lenguaje, la estética y las problemáticas pertinentes a las cuestiones de género e historia cultural (afro-indígena). Los jóvenes de los barrios de autoconstrucción popular están en las escuelas, pero ellas niegan sus marcas identitarias (Arouca, 2017). El estigma de la violencia reproduce la marginalización de las culturas de estos barrios en las instituciones educativas (Marques, 2013). Sin embargo, existen algunas iniciativas que valoran y reconocen la cultura afrodescendiente de las favelas. Como dice Alex, de la Escuela de Capoeira OlORUm (barrio Fagenda Grande):

Muchas veces algunos no tienen acceso a lo esencial. Los profesores no tienen contacto con los alumnos de la periferia. Y después empiezan los problemas por la falta de recursos y la falta de comunicación. territarios 44 Especial 201 


\section{territorias} 44 Especial
La convivencia es importante. En nuestro mundo con tantos ingenieros, la gente no tiene contacto. La capoeira da este contacto (OLORUM, 2019).

Asimismo, en Curuzu, una favela histórica de Libertad, existen múltiples iniciativas que rescatan saberes y prácticas culturales negras. Al respecto, el colectivo Ilê Aiyê expone:

Dentro de 45 años de actividad, el Proyecto de Extensión Pedagógica de Ilê Aiyê, creó Escuelas, metodologías específicas para procesos de formación de profesores, enseñanza-aprendizaje, relación profesoralumno y comunidad, en escuelas regulares de enseñanza fundamental y escuela de música en diferentes áreas de cursos profesionales (Ilê Aiyê, 2019, p. 1).

¿Qué principios deberían fundamentar la educación escolar en las favelas? Durante los últimos 20 años, en Salvador de Bahía se han desarrollado nuevas maneras de resistencia cultural, tales como los Saraus, encuentros libres de poesía, música, prosa; los teatros populares, como el teatro del oprimido; los grupos de capoeira; los muralistas y grafiteros; y los grupos musicales de rap, hip hop, reggae, samba, etcétera.

La mayoría de estas iniciativas hace posibles nuevos encuentros culturales, políticos y antirracistas entre los jóvenes al interior de los barrios periféricos. Asimismo, junto con las prácticas organizadas alrededor de las batucadas y la capoeira, históricamente anteriores, se cambia del habitus de subordinación a un habitus de solidaridad y rebeldía (Petropoulou, 2020). Todo esto, inspirado en las luchas del quilombo do Cabula, existente en el pasado, en la misma zona donde se desarrollan actualmente los barrios periféricos del Norte de Salvador de Bahía.

Según las entrevistas y el trabajo de investigación participativa realizado, estos nuevos espacios de socialización tienen un carácter horizontal, sobre todo en lo que respecta a la toma de decisiones, la cual se realiza a través de asambleas abiertas o semiabiertas. De igual forma, estos se reproducen de manera rizomática, siguiendo las luchas del movimiento negro independiente y el de los indígenas. Además, les ofrecen nuevas perspectivas antipatriarcales y anticapitalistas.

Entonces, en este artículo se defiende una "pedagogía de favela", que reconozca la importancia de la inserción en los currículos escolares, de elementos de lo cotidiano en estos barrios (Arauca, 2017), así como de la tradición de rebeldía quilombola e indígena (Purificação, 2012; Moreira \& Brito, 2017).

Que en las escuelas se haga visible la tradición de rebeldía y sus influencias a diferentes culturas populares de las favelas, puede abrir una vía para la reflexión y la acción colectiva. Las palabras de Rejane, del Quilombo Quingoma, son proféticas y permiten que las escuelas situadas en las periferias piensen la educación de otra manera: 
En las escuelas no existe una educación "diferenciada", estas son escuelas "formales" que distinguen la gente de nuestra comunidad y no valorizan nuestros conocimientos. Queremos formar profesores para promover la cultura. Queremos hacer una escuela Quilombola. Escuchando el son de quilombo. La samba es una herramienta de resistencia. Libera el espíritu y cura nuestro sufrimiento. Las "descenderas", las mujeres que no pegan a los niños, nosotras, sentimos esta energía para ver cómo vamos a organizarnos, nosotras somos felices porque somos guerrilleras, esta lucha va a seguir (Rejane, 2019).

Los resultados de este trabajo muestran que dentro de un desarrollo urbano desigual y un contexto de "capitalismo bio-thánato-político”, emergen algunas iniciativas de resistencias creativas de las llamadas "culturas de rebeldía" que intentan cambiar la escuela y transformarla en un espacio más participativo para los jóvenes de las favelas. En este sentido, demuestra la riqueza intercultural de estos barrios de autoconstrucción popular, en un intento por cambiar la relación conflictiva entre las nociones de escuela y favela.

Las relaciones de solidaridad tejidas en las comunidades de las favelas que se manifiestan en la idea de extender las familias más allá de los lazos parentescos, son uno de los ejemplos que podemos citar para provocar un replanteamiento de las prácticas pedagógicas dentro de las escuelas. Esta solidaridad que se relaciona con la perspectiva de autoconstrucción que estructura la favela en su conjunto, encuentra sus bases en el sentimiento de solidaridad que une a las personas y "pone a todos en el mismo barco". En este barco "entendemos el dolor de los demás y luchamos para que el dolor se cure. Por lo tanto, los problemas que enfrentan los estudiantes en una escuela son también los problemas de todos en la escuela. Asimismo, su potencial es nuestro orgullo". Así, cuando los contextos de violencia atraviesan la realidad escolar y sacan al alumno de la escuela, la dirección de la escuela junto con los docentes y la comunidad escolar pueden pensar en alternativas y trazar caminos juntos para superar la demanda identificada. En consecuencia, la diversidad cultural brinda un campo fértil de posibilidades, considerando que diferentes sujetos tienen diferentes perspectivas sobre una determinada situación. Por eso es importante comprender la importancia de los grupos artísticos, culturales, locales, en la composición de la vida escolar diaria, llevando a la escuela otras prácticas educativas, diálogos, lenguajes, estéticas, saberes y otros elementos que conforman la identidad y cultura de las favelas, resignificando el espacio y el currículo. Así, resulta de gran poder traer a la escuela los sujetos que integran la comunidad en la que viven, reconociendo otros referentes que están fuera del eje hegemónico, asumiendo los saberes, culturas, historias de resistencia local de manera crítica, problematizando tersitorias 44 Especial 203 


\section{territorias} 44 Especial las demandas existentes desde lecturas de base histórica y política, transversalizando los currículos formales con las experiencias que transitan la escuela. La escuela puede ser el lugar de discusión y construcción de otros proyectos de sociedad desde la conexión con el contexto sociocultural en el que se encuentra inmersa.

Por tanto, de la misma manera que los barrios autoconstruidos son el resultado de la autogestión plural de sus vecinos, la escuela puede, desde esta perspectiva, ser el lugar de los cambios necesarios para la comunidad. De ese modo, abrirse a los sujetos que la componen, asumir sus penas, enorgullecerse de sus competencias, discutir sus problemas desde dentro y con la comunidad escolar, son actitudes que ofrecen diferentes formas de replantear la escuela misma con respecto a la diversidad de las culturas que se encuentran en su entorno. Esta problemática es semejante al concepto Aymara del "mundo ch'ixi" descrito por Silvia Rivera Cusicanqui (2018) como un mundo gris que contiene muchos pequeños elementos coloridos en movimiento y respeto mutuo, un mundo de la favela intercultural dinámico, solidario y contradictorio, por lo tanto, visto como muy unido por el exterior. Desde esta perspectiva, ¿podría ser la escuela un espacio para la politización de los sujetos, que contribuya a la búsqueda de caminos que sugieran salidas para el contexto de exclusión étnico-racial? Es un tema que queda abierto al debate.

\section{Referencias}

Afolabi, N. (2016). Mãe Hilda: Matriarchy, Candomblé, and Ilê Aiyê. En Ilê Aiyê in Brazil and the Reinvention of Africa. African Histories and Modernities. Palgrave Macmillan. https://doi. org/10.1007/978-1-137-59870-7_3

Agamben, G. (1998). Homo Sacer: Sovereign Power and Bare Life (Trad. D. HellerRoazen). Stanford University Press. Agamben, G. (2005). State of Exception. University of Chicago Press.

Alberti, V., \& Pereira Araujo, A. (2016). Histórias do movimento negro no Brasil: depoimentos ao CPDOC. Pallas Editora.

Alex \& Emerson. (2018). Representantes del espacio autogestivo de Capoeira Olorum. Entrevista en video a Christy Petropoulou. Archivo personal.

Andrade, A., \& Brandão, P. (2009). Geografía de Salvador. EDUFBA.

Anzaldúa, G. (1987). Borderlands/La Frontera: The New Mestiza. Aunt Lute Books.

Ardito, L. (2014). Cuando don Carnal se viste de negro: la negritud nuestroamericana entre "lo negro" y "lo afrodescendiente". Latinoamérica. Revista de Estudios Latinoamericanos, (59), 223-249. http://www. scielo.org. $\mathrm{mx} /$ scielo.php? pid $=$ S1665$85742014000200009 \&$ script $=$ sci_arttext

Arouca, M de J. (2017). Favelas pedagógicas: distanciamentos e aproximações entre a cultura escolar e a cultura da (o) 
educanda (o) de favela [Tesis de pregrado en pedagogía]. Universidade do Estado da Bahia. https://bibbcl.wixsite.com/bemb/lficha-catalografica

Arroyo, M. (2012). Outros sujeitos, outras pedagogias. Editora Vozes Limitada.

Bajtín, M. (2003). La cultura popular en la Edad Media y el Renacimiento. El contexto de François Rabelais (Trad. J. Forcat \& C. Conroy). Alianza Editorial. (Trabajo original publicado en 1952).

Belausteguigoitia, M. (2009). Borderlands/ La Frontera: el feminismo chicano de Gloria Anzaldúa desde las fronteras geoculturales, disciplinarias y pedagógicas. Debate Feminista, 40, 149-169. https://www.jstor.org/stable $/ 42625120$

Bomfim, N., \& Correia, S. L. (2016). Representações Sociais do Espaço e Ensino de Geografia. Revista Caminhos da Geografia, 17(59), 18-38. https:// doi.org/10.14393/RCG175902

Bourdieu, P. (2005). Habitus. In J. Hillier \& E. Rooksby. Habitus: A sense of place (pp. 43-52). Ashgate.

Brandão, C. R. (2006). O que é educação popular. Instituto Superior de Filosofía Berthier. http://ifibe.edu.br/ arq/201509112220031556922168. pdf

Brumarinho, M. (2019). CARTOGRAFAR Conflictos por la tierra en la Babia [Presentación oral]. Congreso de Ecología Política. Universidad Federal de Bahía.
Campos, A. (2010). Do Quilombo a FavelaA Producao do 'Espaco Criminalizado' no Rio de Janeiro. Editora Bertrand Brasil.

Carril, L. (2006). Quilombo, favela e periferia: a longa busca da cidadania. Annablume.

Carvalho, M. de I., \& Pereira, C. (2014). Organização do território e desigualdades sociais na Região Metropolitana de Salvador. En M. de I. Carvalho \& C. Pereira, Salvador: transformações na ordem urbana (pp. 109-140). Editorial Letra Capital; Observatório das Metrópoles.

Castells, M. (1983). The City and the Grassroots. A Cross Cultural Theory of Social Movement. Edward Arnold Pub.

CEPAIA. (2011). Introducción a la Conferencia de UNEB 2011 [Presentación oral]. Centro de Estudos dos Povos Afroindio Americanos. Salvador de Bahía, Brasil. http://www.uneb.br/cepaia/ files/2011/08/Conferencia8.pdf

CEPAIA. (2015). O que e ser negro na Bahia? [Archivo de vídeo]. En N. Costa da Mata, \& E. Carvalho Lima (realizadores). Centro de Estudios Afro-IndioAmericanos.

CEPAiA. (2019). Real de todas racas, de todas as cores e de todos os credos. 11 motivos para voce entender que e Brazil es un pais racista [Presentación oral]. Día de conmemoración de la lucha negra. Centro de Estudos dos Povos Afro-indio Americanos. Salvador de Bahía, Brasil. territarios 44 Especial 205 
Collins, P. H. (2000). Gender, Black Feminism, and Black Political Economy. The Annals of the American Academy of Political and Social Science, 568(1), 41-53. https://doi. org/10.1177/000271620056800105

Damianakos, S. (2003). La Grèce dissidente moderne: cultures rebelles. Editions L'Harmattan.

Deffner, V. (2010). Geografia da desigualdade social: Uma perspectiva de geografia urbana crítica apresentada a partir do exemplo da produção social da favela em Salvador-BA. GeoTextos, 6(2), 115137. https://doi.org/10.9771/19845537 geo.v6i 2.4833

Dowbor, L. (2006, 3 de abril). Educação e Desenvolvimento [Archivo PDF]. http:// falphaville.agenciafrutifera.com.br/ wp-content/uploads/2014/03/ Educac\%CC\%A7a\%CC\%83o-e-Desenvolvimento.pdf

Fereira, E. (2008). A multidão rouba a cena: o quebra-quebra em Salvador (1981) [Trabajo de posgrado]. UFBA. https://repositorio.ufba.br/ri/handle/ri/11252

Fernandes, C. M., \& Carvalho, I. de M. (2014). Organização do território e desigualdades sociais na Região Metropolitana de Salvador. En M. de I. Carvalho \& C. Pereira, Salvador: transformações na ordem urbana (ecapítulo 6). Editorial Letra Capital; Observatório das Metrópoles.
Foucault, M. (2004). Naissance de la biopolitique. Cours au Collège de France 1978-1979. Ehess Gallimard Seuil.

Freire, P. (1987). Pedagogía do Oprimido. Paz e Terra.

Freire, P. (2015). La educación como práctica de la libertad. Siglo XXI editores.

Garcia, J. (Ed.). (2008). 25 anos 1980-2005: movimento negro no Brasil. Fundação Cultural Palmares.

Garmany, J., \& Richmod, M. (2020). Hygienisation, Gentrification, and Urban Displacement in Brazil. Antipode, 52(1), 124-144. https://doi. org/10.1111/anti.12584

Gobernación del Estado de Bahía. (2014, 5 de junio). [Ley 13.182]. http://www. mpsp.mp.br/portal/page/portal/GT_ Igualdade_Racial/Outros/Lei\%20 13.182\%2006.06.14\%20Bahia.pdf

Haesbaert, R. (2014). Viver no limite: Território e multi/transterritorialidade em tempos de insegurança e contenção. Editora Bertrand Brasil.

Håndlykken-Luz, Å. (2019). Polyhedron of Powers, Displacements, SocioSpatial Negotiations and Residents' Everyday Experiences in a "Pacified" Favela. ACME: An International Journal for Critical Geographies, 18(6), 1321-1346. https://www.acme-journal.org/index.php/acme/article/ view/1835/1511

Hasenbalg, C., \& Silva, N. (1991). Estrutura social, mobilidade e raça. Instituto Universitário de Pesquisas do Rio de Janeiro. 
Hobsbawm, E. (2007). La era de la revolución-1789-1848. Editorial Crítica.

Holloway, J. (2010). Crack capitalism. Pluto Press. http://www.ipea.gov.br/ portal/images/stories/PDFs/livros/ livros/livro_retradodesigualdade_ed4. pdf

Ilê Aiyê (2019). Mãe Hilda Jitolú-Guardiã da Fé e da Tradição Africana. [Entrada de blog] Ilê Aiyê. http://www.pordentrodaafrica.com/cultura/olodum-eos-30-anos-de-farao/attachment/yle

Instituto Brasileiro de Geografia e Estatìstica (IBGE). (2013). Censo Demográfico 2010: Aglomerados Subnormais - Informações Territoriais. Ministério do Planejamento, Orçamento e Gestão e IBGE. https://biblioteca.ibge. gov.br/visualizacao/periodicos/552/ cd_2010_agsn_if.pdf

Instituto de Pesquisa Econômica Aplicada (IPEA). (2011). Retrato das desigualdades de gênero e raça (4. Ed.). IPEA.

Keisha-Khan, Y. P. (2013). Black Women against the Land Grab: The Fight for Racial Justice in Brazil. University of Minnesota Press.

Lefebvre, H. (1968). Le Droit à la ville. Editorial Anthropos.

Liscano M., \& González D. (Comp.). (2018). Leyendo el Carnaval. Miradas desde Barranquilla, Babia y Barcelona. Universidad del Norte.

Mansilla Quiñones, P., \& Imilan Ojeda, W. (2020). Colonialidad del poder, desarrollo urbano y desposesión Mapuche: urbanización de tierras mapuche en la
Araucanía Chilena. Scripta Nova. Revista Electrónica de Geografía y Ciencias Sociales, 24(630), 1-23. https:// revistes.ub.edu/index.php/ScriptaNova/article/viewFile/21225/30806

Maricato, E. (1982). Autoconstrução, a arquitetura possível. En E. Maricato (Org.), A produção capitalista da casa (e da cidade) no Brasil industrial (pp.71-93). Alfa-Omega. https:// erminiamaricato.files.wordpress. com/2012/03/a-produccca7acc83ocapitalista-da-casa-e-da-cidade-no-brasil-industrial.pdf

Marques, R. (2013). Que escola é essa que nós queremos? Produção de sentidos de uma escola nas perspectivas docentes [Tesis de Doctorado en Educación]. Universidade Federal Fluminense Centro De Estudos Sociais Aplicados.

Mattos, W. R. (2003). Ações Valores civilizatórios afro-brasileiros, políticas educacionais e currículos escolares. Revista da FAEEBA - Educação e Contemporaneidade, 12(19), 229-234.

Mbembe, A. (2003). Necropolitics. Public Culture, 15(1), 11-40. https://doi. org/10.1215/08992363-15-1-11

Moreira, A. M., \& De Brito, J. E. (2017). As contribuições do movimento quilombola na construção de uma proposta de educação especifica. $R e$ vista da FAEEBA - Educação e Contemporaneidade, 26(49), 119-137. https://doi.org/10.21879/faeeba2358-0194.2017.v26.n49.pl19-137 tersitarios 44 Especial 207 
Movimiento Negro Unificado (MNU). (1988). 1978-1988, 10 anos de luta contra o racismo. Confraria do Livro.

Nascimento, A. (2019). O Quilombismo. Documentos de una militância Panafricanista. Instituto de Pesquisas e Estudos Afro Brasileiros IPEAFro; Perspectiva.

Neto, L. (2017). Una historia do samba: volumen I (As origens). Editora Companhia das Letras. https://staticsshoptime.b2w.io/sherlock/books/ firstChapter/131407661.pdf

Nobre, E. (2002). Urban regeneration experiences in Brazil: Historical preservation, tourism development and gentrification in Salvador da Bahia. Urban Design International, 7(2), 109-124. https://doi.org/10.1057/ palgrave.udi.9000066

Nuttall, S., \& Mbembe, A. (Ed.). (2008). Johannesburg: The Elusive Metropolis. Duke University Press.

Olodum. (2005). Olodum 25 años (Ao Vivo No Festival De Verão Salvador). [Dvd] Dirigido por Aloysio Legey.

Petropoulou, C. (2014). Crisis, Right to the City movements and the question of spontaneity: Athens and Mexico City. City: analysis of urban trends, culture, theory, policy, action, 18(4-5), 563-572. https://doi.org/10.1080/13604813. 2014.939478

tersitarias 44 Especial 208 dad y movimientos sociales contem-
poráneos. Por un movimiento social
urbano-regional...jpoético? Desde
Nezahualcoyotl al mundo. En C. Petropoulou, A. Vitopoulou, \& C. Tsavdaroglou (Eds.), Urban and Regional Social Movements (pp. 462-485). Invisible Cities Research Group.

Petropoulou, C. (2018a). Social resistances and the creation of another way of thinking in the peripheral self-constructed popular neighbourhoods: Examples from Mexico, Argentina, and Bolivia. Urban Sci, 2(1), 1-27. https://doi. org/10.3390/urbansci2010027

Petropoulou, C. (2018b). "Ciudad solidaria" vs "ciudad alienada": cambiando la ciudad por medio de cooperativismo solidario. ¿Grietas a la ciudad de trabajo alienado?. Ejemplos en Argentina y Grecia. En M. Alcántara, M. García Montero \& F. Sánchez López (Coords.), Memoria del $56^{\circ}$ Congreso Internacional de Americanistas (pp. 200-211). Ediciones Universidad de Salamanaca.

Petropoulou, C. (2020). Ciudades invisibles y cambio de habitus: narrativas cartográficas, poéticas y rebeldes. Ejemplos de Ciudad Bolívar (Bogotá) y Comuna 13, San Javier (Medellín). En A. F. Azevedo, S. Kozel \& N. Rego, Narrativas, Geografias, Cartografiaspara viver, é preciso espaço e tempo (pp. 669-723). Universidade do Minho; UFPR; UFRGS.

Prezia, B. (2017). História de resistência indigena. 500 anos de luta. Expressão popular. 
Purificação, J. O. (2012). Luta, Vivência e Lei: Aportes para refletir um projeto educação escolar com perspetivas Quilombolas. Revista da Associação Brasileira de Pesquisadores/as Negros/ as (ABPN), 3(6), 47-60. https://abpnrevista.org.br/index.php/site/article/ view $/ 351 / 325$

Queiroz, D. M. (2002). Desigualdades raciais no ensino superior no Brasil. Um estudo comparativo. O negro na universidade. Salvador: Novos Toques, (5), 13-55.

Quijano, A. (2000). Colonialidad del poder, eurocentrismo y América Latina. En E. Lander (Comp.), La colonialidad del saber: eurocentrismo y ciencias sociales. Perspectivas latinoamericanas (p. 246). Consejo Latinoamericano de Ciencias Sociales (CLACSO). http://bibliotecavirtual.clacso.org.ar/ar/libros/lander/ quijano.rtf

Rajchenberg, E. (2015). De la rebelión a la resistencia: De Eric Hobsbawm a James C. Scott. Bajo el Volcán, 15(22), 41-59.

Ramos, V., Guimarães, R., Redivo, A., \& De Carvalho, O. (2013). Mapeamento das áreas susceptíveis a escorregamentos rasos no subúrbio ferroviário de Salvador (BA), utilizando os parâmetros físicos diferenciados para cada classe de solo [ponencia]. X Simposio Brasileiro de Geografía Física Aplicada. http://www.cibergeo.org/XSBGFA/ eixo3/3.4/198/198.htm

Reevo. (2016). La educación probibida. 2009-2016. Documental. Reevo. Red de
Educación Alternativa. http://www. educacionprohibida.com/? $1=\mathrm{es}$

Reis, J. J. (1995). Slave Rebellion in Brazil: The Muslim Uprising of 1835 in Bahia. The Johns Hopkins University Press. Rejane. (2019). Entrevista a Christy Petropoulou sobre la historia de las luchas de Quilombo Quingoma (Lauro de Freitas, Salvador de Bahia). [video]. Archivo personal.

Ribeiro, D. (2017). O que é lugar de fala?. Editora Letramento.

Riggio, M. C. (2004). Carnival: Culture in action-the Trinidad experience. Routledge.

Rivera Cusicanqui, S. (2018). Un mundo ch'ixi es possible. Ensayos desde un presente en crisis. Tinta Limon.

Sant'ana, A. O. (2005). História e conceitos básicos sobre o racismo e seus derivados. En K. Munanga (Org.), Superando o racismo na escola (pp. 39-67). Ministério da educação, Secretaria da educação continuada, Alfabetização e Diversidade. http://portal.mec.gov. br/secad/arquivos/pdf/racismo_escola.pdf

Santos Silva, J. D. (2009). Rap: Uma experiência pedagógica na reafirmação da cultura da criança negra [Tesis de pregrado]. Unviersidade Do Estado Da Bahia, UNEB.

Santos, J. T. Dos. (2018). O poder da cultura e a cultura no poder. Editora da Universidade Federal da Bahia, EDUfBA. territarios 44 Especial 209 
Santos, M. (1975). L'espace partagé: les deux circuits de l'économie urbaine des pays sous-développés. Editions M. Th. Genin.

Santos, M. (2008). O centro da cidade do Salvador. Editorial da Universidade de São Paulo; Editorial da Universidade Federal da Bahia, EDUfBA. (Trabajo original publicado en 1959).

Sarau Da Onça. (2017). O diferencial da Favela. Poesías e contos de Quebrada.

Sarau Da Onça. (2019). O diferencial da Favela. Dos contos as poesías de Quebrada.

Schaun, Á. (2002). Práticas educomunicativas: grupos afro-descendentes, Salvador, Bahia: Ara Ketu, Ilê Aiyê, Olodum, Pracatum. Mauad Editora.

Scott, J. (1990). Los dominados y el arte de la resistencia: discursos ocultos. Ediciones Era.

Senado de Brasil. (1996, 20 de diciembre). Lei de diretrizes e bases da educação nacional. [Ley 9.394]. http://www2. senado.leg.br/bdsf/bitstream/handle/id/529732/lei_de_diretrizes_e_ bases_led.pdf

Silva, A. da C. (2003). Por uma representação social da negro mais próxima e familiar. En LM. de Assunção Barbosa, PB. Gonçalves \& VR. Silvério (Orgs.), De preto a afro-descendente: trajetórias de pesquisa sobre relações étnico-raciais no Brasil (pp. 151-164). Editora da UFSCar.

tersitarias 44 Especial 210 a definição de favela). Lugar Comum-Estudos de Midia, Cultura e
Democracia, (39), 37-43. https:// uninomade.net/wp-content/files_ $\mathrm{mf} / 111206131220$ ProvaFinal2_LugarComum39.pdf\#page $=37$

Silva, J. de S., Barbosa, J. L., De Oliveria Biteti, M., \& Fernandes, F. L. (Orgs.). (2009). O que é favela, afinal?. Observatório de Favelas; BNDES. http:// observatoriodefavelas.org.br/wpcontent/uploads/2013/09/o-que$\% \mathrm{C} 3 \%$ A9-favela-afinal.pdf

Silva, L. da L. (2008). Breve resgate histórico da luta por moradia em Salvador: o caso da ocupação Quilombo de Escada. $A n$ titeses, 1(1), 118-150. https://www.redalyc.org/pdf/1933/193317377006. pdf

Souza, Â. G. (2001). Favelas, invasões e ocupações coletivas nas grandes cidades brasileiras - (Re) Qualificando a questão para Salvador- BA. Cadernos Metrópole, (5), 63-89. https://revistas. pucsp.br/metropole/article/viewFile $/ \% 209297 / 6901$

Souza, Â. G. (2008). Limites do habitar: segregação e exclusão na configuração urbana contemporânea de Salvador e perspectivas no final do século $X X$. Editorial da Universidade Federal da Bahia (EDUFBA).

Souza, J. (2018). A elite do atraso: da escravidão à Lava-Jato: À guisa de um debate. Leya.

Susuarana. (2018). Presentación des libros y entrevista oral a Christy Petropoulou. [video]. Archivo personal. 
UNFPA. (2013). Informe Juventud y Politicas Públicas en Salvador-Babia. Fondo de Población de las Naciones Unidas.

Valladares, L. do P. (2005). A invecao da favela. Do mito de origen a favela.com. Editora Fundación Getulio Vargas.

Vasconcelos, P. de A. (2016). Salvador. Transformações e permanências (15491999). Editora da Universidade Federal da Bahia, EDUfBA.

Villoro, L. (1950). Los grandes momentos del indigenismo a México. Colegio de México; Fondo de Cultura Económica.

Villoro, L. (2007). Los retos de la sociedad por venir. Fondo de Cultura Económica.

Virilio, P. (2004). Ville panique. Ailleurs Commence Ici. Editions Galilée.

Wacquant, L. (2014). Marginality, ethnicity and penality in the neo-liberal city: an analytic cartography. Ethnic and Racial Studies, 37(10), 1687-1711. https://doi.org/10.1080/01419870 .2014 .931991
Wacquant, L. (2016). A Concise Genealogy and Snatomy of Habitus. The Sociological Review, 64(1), 64-72. https:// doi.org/10.1111/1467-954X.12356

Waiselfisz, J. J. (2016). Mapa de violencia 2016. Homicidios por armas de fogo no Brasil. Facultad Latinoamericana de Ciencias Sociales, FLACsO. http:// flacso.org.br/files/2016/08/Mapa2016_armas_web-1.pdf

Walter Porto-Gonçalves, C. (2009). De saberes y de territorios: diversidad y emancipación a partir de la experiencia latinoamericana. Polis, $8(22), 121$ 136. https://journals.openedition. org/polis/2636

Zaluar, A., \& Alvito, M. (2006). Um seculo de favela. Editora Fundación Getulio Vargas.

Zanirato, S. H. (2004). A restauração do Largo do Pelourinho: edificações tão bonitas de se ver, histórias não tão bonitas de se contar. Dimensões-Revista de História da Ufes, (16), 323-344. 